\title{
Differential Gear Box To Reduce Vibration Using Different Materials For Vehicles-A Review
}

\author{
Prasad Matam a, Dr. Nilesh Diwakar ${ }^{b}$ and Dr. A. Rajasekhar ${ }^{c}$ \\ ${ }^{a}$ Research Scholar, Dept. of Mechanical Engineering, \\ Sri Satya Sai University of Technology \& Medical Sciences, Sehore, Bhopal Indore Road, Madhya Pradesh, India \\ ${ }^{\mathbf{b}}$ Research Guide, Dept. of Mechanical Engineering, \\ Sri Satya Sai University of Technology \& Medical Sciences, Sehore, Bhopal Indore Road, Madhya Pradesh, India \\ ${ }^{c}$ Research Co-Guide, Methodist College of Engineering and Technology
}

Article History: Received: 11 January 2021; Accepted: 27 February 2021; Published online: 5 April 2021

\begin{abstract}
Whatever framework is embraced to coordinate the automobile to its thought process unit — be it a hand shift gearbox, a 'hot' shift gearbox or completely automatic unit, a complex and generally expensive mechanism is ordinarily included. More than expected plan office consideration is centeredaround this region of a recently imagined vehicle. Grounded plan systems for transmission gearing were accessible before the principal automobile or even the inner combustion motor was created; solid answers have in this way been generally accessible from the planning phase. The intricacy of the mechanisms has additionally requested, on account of amount delivered vehicles, thorough drawing designs of the variety of segments included with the goal that resilience stacking can be read and the requirement for exceptionally talented fitting, during get together, decreased. The present-day meaning of the creator's commitment is additionally improved by the need to guarantee without a doubt the base of expensive turn of events or creation changes. The cautious determination of gear ratios for a manual unit, or of control boundaries in an automatic one, can drastically influence the presentation or driveability of the completed vehicle.
\end{abstract}

\begin{abstract}
Introduction
With numerous points of interest, for example, tight structure, high efficiency and stable speed proportion and so on, gear train has been generally utilized in numerous mechanical fields. At the point when the gear reducer is running, gearbox vibration is produced, because of the impact of the gear pair dynamic lattice power, which not just influences the soundness of the transmission framework, yet in addition creates commotion. What's more, inordinate commotion delivered by a reducer causes group exhaustion, stressed correspondence, and conceivable hearing harm. To guarantee a calm, smooth, and safe activity of a gear transmission framework, it is important to comprehend mechanisms of the powerful reaction and clamor radiation of the gear reducer, then, their decrease is profoundly wanted.

With the expanding interest for calmer gear frameworks, a lot of work has been accounted for in the writing on examining the vibration and commotion of the gearbox. Mohamed et al. constructed the gearbox vibro-acoustic framework by utilizing a three-dimensional limited component (FE) approach, and the acoustic reaction of the framework was assessed. Velex and Maatar processed the unique reaction to work solidness variety for mathematical gears. Their outcomes showed the effect of lattice firmness minor departure from dynamic reaction and tooth loads. Jean et al. built up a trial and mathematical investigation of dynamic marvels including gear impacts with one free gear inside an auto gearbox. Barthod et al. managed the clatter clamor, brought about by variance of the motor force under unique conditions, which could cause different effects inside the gearbox. Kato et al. mimicked the vibration and commotion radiation of a solitary stage gearbox by joining limited component (FE) vibration investigation with limit component clamor examination. The aftereffects of this examination very much concurred with the comparing estimated information. Spike and helical gears were tried in the NASA gearcommotion apparatus to analyze the clamor created by various gear plans. Valuable decisions about the impact of the gear plan boundaries on gearbox emanated clamor were drawn.
\end{abstract}

\section{Literature Review}

Portal axle is a superior trade for typical back tire hub in rough terrain driving conditions. It is intended to give more ground leeway to the differential unit. Prod gears are displayed and mimicked to discover its dynamic conduct. Modular examination was done on three diverse mix of gear trains in the gearbox utilizing FEM under both pre-stress and free pressure conditions. Through modular examination reverberation qualities of a construction can be anticipated. Mass and firmness of a framework impacts the general unique reaction of a framework. Initial six mode shapes and eight regular frequencies were found. Nobody characteristic recurrence coordinated with working recurrence. Modular examination of mechanical framework permits forecast of characteristic frequencies and relating mode shapes. Firmness of a design changes as indicated by the heap variety. Modular examination was done in effect pound under various stacking conditions with shifting cross section solidness.

Normal recurrence increments with increment in burden. AnkurSaxena et al have researched the impact of lattice solidness on mode shapes and normal frequencies of geared rotor framework. Modular investigation includes 
assessment of modular damping factors, characteristic frequencies, basic paces, mode shapes and recurrence reaction capacities and so on Over a period, tooth breakage, breaks may create in gear tooth which modifies the lattice solidness. Isa Yesilyurt et al have estimated the decrease of gear tooth solidness utilizing modular investigation. Modular investigation additionally serves to discover the harm recognition of gear tooth and wear harm. Test has been completed to acquire FRF of the gear tooth. Steel tipped effect hammer utilized as exciter and accelerometer go about as a reaction indicator. Peter Weis [5] et.al was expected to register initial 20 regular frequencies and its relating mode states of gearbox lodging under pre-focused on condition in ANSYS workbench.

Ashwanikumar et al has played out the modular examination of weighty truck gearbox with four unique materials. Gear abandons, transmission mistake and burden changes are the chief reason for vibration. Initial twenty mode shapes are gotten and better material has been chosen. Not just the material properties, the design of the gear is additionally impact the common frequencies. More noteworthy the youthful's modulus causes more prominent the characteristic recurrence and existence with less commotion. It is conceivable to stay away from reverberation without adjusting properties yet by modifying structure.

In gears, dynamic flaws can be analyzed by two techniques like customary range investigation and wavelet change. Fourier Transform is a broadly utilized vibration analyzer. FT can be utilized at when sign is non-fixed. To defeat this issue by presenting Wavelet Transform. Blend of Time and Frequency areas can be handled in WT. AditendraJaiswal et.al have examined various methods of gear disappointment under powerful condition utilizing FFT analyzer. Range of a deficiency in the deficient gear is contrasted and new gear. Dynamic investigation is a proficient technique for condition checking in day today life. The ascent in vibration design uncovers the imperfections in turning segments. In vibration examination quickening, speed and relocation are estimated dependent on our decision. Vibration investigation not just used to identify flaw, are likewise utilized discover load changes. Time recurrence space examination is a productive strategy to analyze the vibration signals.

UtkarshPatil et al. talked about in this paper the transmission arrangement of the vehicle yet they fundamentally centeredaround the distinctive kind of the differential gearboxes. As the vehicle gets stucked in the potholes, mud, dangerous street, day off the obstruction and so on the force gave to the stucked wheel is more and the vehicles tyre pivot on a similar spot and doesn't push ahead so to limit this restriction the creators talked about different adjustment in the differential gearboxes, for example, helical gear driven differential, restricted slip differential, grip pack differential, cykro gear differential, electronic controlled differential, belt driven differential, locking differential by radial power and so forth this numerous differentials are intended for specific purposes tasks and these can't kill all the limits thus, we can utilize its mix and dispose of the constraint and use in the vehicle for our necessary activity.

HarshaBhandaru et al. examined about the differential gearbox and gearbox to diminish the transmission framework utilizing differential gear and he additionally examined about different transmission framework, for example, gear cluster, toroidal CVT, CVT, Lock differential rather than differential.

Bridjesh $\mathrm{P}$ et al. suggested that the plan, demonstrating and the primary examination of chain differential. They found the outcomes utilizing solidworks on the various materials. He dissected the differential stub hub, sprocket and involute slope gear by aluminum composite, plain carbon steel and dim cast iron. They notice the pressure, strain and relocation esteem and inferred that the aluminum composite is alright for differential body, dim cast iron for sprocket and for the gear steel is the protected material.

Chandrakant Singh et al. gives the data about vehicle differential framework. At the point when one wheel of the vehicle is stucked in the day off mud and needs more foothold for example fixed then the other wheel turns double its ordinary speed, so he contemplated and gave its arrangement by presenting differential locking framework which is sensor based. Sensor detects the distinction in speed of the vehicles haggles the differential so the wheels have same foothold. This mechanism delivers an adjustment power acting however the back hub that oppose a vehicle revolution. In this paper the differential is going to bolted and the shifter mechanism used to move canine ring draw in both wheel shaft with drive and equivalent force is given to the both.

Silvia Medvecka-Benova et al. examined and have done streamlining of the differential substantial truck without a wheel decrease. The exceptional developments idea arrangement has a hefty truck in light of the fact that the dispersion of the drive force is put in the focal conveyance tube, as demonstrated in Fig. 5 The changed differential gearbox comprises of the Axial pivot, slant pinion, Bevel gear, half hub, Drive shaft of the back hub, Ring gear. By doing the examination the creator found that the outcome that the first differential gearbox there was expanded pressure with the worth surpassing the yield strength of the material gearbox in the spot of the score at the top of the gearbox, so by change of the differential gearbox the estimation of the pressure will be diminished at the indent by $34 \%$ and this is changed gearbox is helpful for bigger burden conveying vehicles like hefty trucks.

Joseph Gerald et al. [6] give the thought regarding the light weight spike gear differential framework by presenting a prod gear at half shaft of the vehicle which send the capacity to the wheel. The transporter is mounted on the propeller shafts which pivots the pinion inverse way. This pinion is associated with the half shaft 
of the vehicle which turn a similar way as propeller shaft. These differential cases $30 \%$ lighter than the slant prod differential and $70 \%$ free space accessible as a result of its thin plan consequently it builds effectiveness and lessening the expense contrasted and others customary differential. This is utilized for light obligation and business vehicles.

Gregory Antoni et al. examined in subsequently paper about different mechanical misfortunes in differential gearbox. In differential gearbox grinding misfortunes is the serious issue it harms the outside of the gear tooth. The grinding misfortune is created in light of the absence of grease between mechanical component or by imperfection in the gear plan. He examined on the grating misfortunes happened utilizing different relationship diagrams. To test the impact of these boundaries and decide the capacity of model to foresee any mechanical misfortunes an affectability investigation was led utilizing mathematical methodology and test study he determined practical qualities for certain boundaries.

Amir Khan et al. examined about the four wheel drive. It can't work without focal differential. They examined the wonder of windup which is there in little distinction in the middle of front and back tire produce additional force applied across the transmission. This contextual analysis is for Maruti Suzuki Zypsy. It moves force proportion 50:50 for front and back pivot however the force create by motor should proportion 60:40 which is ideal proportion for better dealing with. Along these lines, it need to supplant gearbox to adjusted focal differential having two diverse side gears. FEM strategy is utilized for investigation and creo-2 is utilized for ascertaining plan. They reasoned that altered focal differential is preferable is better over exchange gearbox.

$\mathrm{C}$ Veeranjaneyulu et al. examined and concentrated on the on the plan and examination of differential gearbox. They investigate utilizing distinctive material, for example, cast iron, cast steel and aluminum composite. The plan is finished with assistance of the universe programming which is utilized for the limited component strategy to invigorate the working state of plan of plan and it likewise anticipate the conduct of the material. From this paper he reasoned that aluminum composite has the pressure an incentive inside as far as possible. So aluminum amalgam is ok for differential gearbox. Subsequent to looking at pressure an incentive for speed, they inferred that the estimation of admissible pressure of aluminum composite is not exactly the other material. They additionally noticed the recurrence examination of the material. The vibrations are less in the aluminum amalgam instead of the other cast iron and cast steel. They reasoned that aluminum compound has multiple times decrease in weight than other two material which builds the mechanical effectiveness of the differential so aluminum composite is the best material utilized for it.

Nitin Kapoor et al. plan and built up a model of differential gearbox with a material of glass filled polyamide composite material by utilizing CATIA-V5 under the distinctive speed and static stacking condition. The pressure and strains aftereffect of glass filled polyamide composite and metallic materials. glass filled polyamide have the better rigidity, recyclability, low thickness, high drag obstruction exhaustion strength, low von-misses pressure, less contact and minimal effort. by relating composite material diverse gearbox with regular it is discovered to be pressure and strains are lower for the composite material which increments mechanical effectiveness.

G. Shrikant Reddy et al. planned and investigated the gear get together in the differential gearbox. the issue of the disappointment at the contact districts limited by altering gear material in static and dynamic condition. This alteration was finished by utilizing stresses and dislodging at the point the material utilized by them are $\mathrm{Ni}-\mathrm{Cr}$ steel and steel and thought about it in the ANSYS workbench. Thus, they got that Ni-Cr steel is the best material in differential gearbox fabricating as it invigorates high likewise the material $\mathrm{Ni}-\mathrm{Cr}$ has long life contrasted with steel.

Gabriele Vandi et al. have introduced the execution of an improved on motor driveline model to finish a current vehicle dynamic model. The motor model depends on guides which are communicated as capacity of motor speed and burden demand. Lei Yulong et al. have zeroed in his examination on a double grip automatic transmission of its water driven framework. We can figure the design size of each body through hypothesis and useful calculation. The unique reenactment model of pressure driven arrangement of double grasp automatic transmission was set up. S" ureyyaNejatDogan have explored the reason for shaking and clacking commotion and presumed that torsional vibration is the primary explanation of vibration. Shawki $\mathrm{S}$ et al. have utilized vibration reaction examination strategy for the scientific investigation of vehicle gearbox framework. He has performed logical and trial examination of a vehicle transmission framework. By utilizing actual properties, he has determined the radiation effectiveness, and the vibration reaction was estimated.

Ashwani Kumar et al. have considered the truck transmission lodging utilizing dark cast iron FG260 as lodging material. The creators have discover the regular recurrence and mode states of lodging, normal recurrence shifts from (1002-2954) Hz. Fujin Yu et al. have considered the automobile transmission gearbox. They have utilized primary advancement strategy to diminish the clamor and vibration of gearbox. Mohamed Slim Abbes et al. have played out the mathematical recreation of the general unique conduct of an equal helical gear transmission. A unique sub organizing strategy was utilized to decide the normal frequencies and the relating mode shapes.

\section{Conclusion}


The material utilized for assortment of differential gearbox ought to be aluminum combination as it diminishes the weight and the gear ought to be comprised of steel because of its solidarity. In the advancement of changed differential gearbox distinctive framework can be utilized. Till now the differential used to take one information and two yields yet by changing and adding one additional incline gear change on crown wheel we can take one info and three yields. Also, by investigating utilizing various materials we can adjust differential gearbox having three yields. Likewise, there are different specific reason differential gearbox yet independently they can't conquer all the impediments so we can utilize the blends of these unique reason differential gearboxes and diminish the limits somewhat.

\section{REFERENCES}

1. Ooi J, Wang X, Tan C, Ho JH, Lim YP. Modal and stress analysis of gear train design in portal axle using finite element modeling and simulation. Journal of Mechanical Science and Technology. 2012 Feb 1;26(2):575-89.

2. Mbarek A, Hammami A, Del Rincon AF, Chaari F, Rueda FV, Haddar M. Effect of load and meshing stiffness variation on modal properties of planetary gear. Applied Acoustics. 2017 Aug 18.

3. Saxena A, Chouksey M, Parey A. Effect of mesh stiffness of healthy and cracked gear tooth on modal and frequency response characteristics of geared rotor system. Mechanism and Machine Theory. 2017 Jan 1;107:261-73.

4. Yesilyurt I, Gu F, Ball AD. Gear tooth stiffness reduction measurement using modal analysis and its use in wear fault severity assessment of spur gears. NDT \& E International. 2003 Jul 1;36(5):357-72.

5. Weis P, Kučera L, Pecháč P, Močilan M. Modal Analysis of Gearbox Housing with Applied Load. Procedia engineering. 2017 Jan 1;192:953-8.

6. Kumar A, Patil PP. Modal Analysis of Heavy Vehicle Truck Transmission Gearbox Housing Made From DifferentMaterials. Journal of Engineering Science and Technology. 2016 Feb 1;11(2):252-66.

7. Niu S. Modal Analysis of Cylindrical Gear Based on Finite Element Model. system.;2(1):3.

8. Vernekar K, Kumar H, Gangadharan KV. Gear fault detection using vibration analysis and continuous wavelet transform. Procedia Materials Science. 2014 Sep;5:1846-52.

9. Jaiswal A, Zakiuddin KS, Shukla VV. Fault Diagnosis of Gear by Vibration Analysis. International Journal of Latest Trends in Engineering and Technology (IJLTET). 2013 Sep;3(1):26-32

10. Diwakar G, Satyanarayana MR, Kumar PR. Detection of Gear fault using vibration analysis. International Journal of Emerging Technology and Advanced Engineering, ISSN. 2012 Sep:2250-459.

11. Vengatesan, K., Kumar, A., Karuppuchamy, V., Shaktivel, R., \& Singhal, A. (2019). Face Recognition of Identical Twins Based On Support Vector Machine Classifier. In 2019 Third International conference on I-SMAC (IoT in Social, Mobile, Analytics and Cloud)(I-SMAC) (pp. 577-580).

12. Shahapurkar SS, Pansare HS, Dhebe PP, Wagh CS, Desale A. Detection of Fault in Gearbox System Using Vibration Analysis Method.

13. Devan PD, Senthilkumar KM, Arun KK. Investigation on Static Stress Analysis of Portal Axle Gearbox. International Journal of Applied Engineering Research. 2018;13(7):524450.

14. UtkarshPatil, Vishal J. Savant, Rohit S. Bharamgonda, Prof. P. N. Gore, "Recent Advances in differential drive system for Automobile Propulsion", International Research Journal of Engineering and Technology (IRJET) Volume 05 Issue 05 May 2018.

15. SreeHarshaBandaru, "Alternative Transmission System For 4-Wheeler" International Journal of Mechanical Engineering and Robotic Research", ISSN 2278 - 0149 Vol. 4, No. 1, January 2015.

16. Kumar, A., Kumar, P., Srivastava, A., Kumar, V., Vengatesan, K., \& Singhal, A. (2020). Comparative Analysis of Data Mining Techniques to Predict Heart Disease for Diabetic Patients. In International Conference on Advances in Computing and Data Sciences (pp. 507-518).

17. Bridjesh P, Vinayak J, Teja $\mathrm{N}$ and Madhu S, "Design of Chain Differential for a Race Car", International Journal of ChemTech Research, CODEN (USA): IJCRGG, ISSN: 0974-4290, ISSN(Online):2455-9555 Vol.10 No.3, pp 225-228, 2017.

18. Chandrakant Singh, Lalit Kumar, Bhumesh Kumar dewangan, Prakash Kumar sen, Shailendra Kumar bohidar, "A Study on Vehicle Differential System", International Journal of Scientific Research and management, Volume2 Pages 1680-1683 ISSN(e):2321- 3418, 2014.

19. Silvia Medvecka-Benova, Frantisek Trebuna, Peter Frankovsky, "Modification of the Centre Differential Gearbox", American Journal of Mechanical Engineering, Vol. 3, No. 6,2015, pp 240-243. 